\title{
SUMMARY OF TRANSITION RESULTS FROM THE F-16XL-2 SUPERSONIC LAMINAR FLOW CONTROL EXPERIMENT
}

\author{
Laurie A. Marshall ${ }^{*}$ \\ NASA Dryden Flight Research Center \\ Edwards, California
}

\begin{abstract}
A variable-porosity suction glove has been flown on the F-16XL-2 aircraft to demonstrate the feasibility of this technology for the proposed High-Speed Civil Transport. Boundary-layer transition data on the titanium glove primarily have been obtained at speeds of Mach 2.0 and altitudes of $15,240-16,764 \mathrm{~m}$ $(50,000-55,000 \mathrm{ft})$. The objectives of this flight experiment have been to achieve $0.50-0.60$ chord laminar flow on a highly swept wing at supersonic speeds and to provide data to validate codes and suction design. The most successful laminar flow results have not been obtained at the glove design point, a speed of Mach 1.9 at an altitude of $15,240 \mathrm{~m}(50,000 \mathrm{ft})$; but rather at a speed of Mach 2.0 and an altitude of $16,154 \mathrm{~m}$ $(53,000 \mathrm{ft})$. Laminar flow has been obtained to more than 0.46 wing chord at a Reynolds number of $22.7 \times 10^{6}$. A turbulence diverter has been used to initially obtain a laminar boundary layer at the attachment line. A lowersurface shock fence was required to block an inlet shock from the wing leading edge. This paper discusses research variables that directly impact the ability to obtain laminar flow and techniques to correct for these variables.
\end{abstract}

\section{NOMENCLATURE}

A area of the region

$B L \quad$ butt line, $\mathrm{cm}$

c chord

$C_{q} \quad$ suction coefficient, $-\frac{m_{\text {flow }}}{\rho_{\infty} U_{\infty}}$

* Aerospace Engineer, Aerodynamics Branch.

Copyright (c) 2000 by the American Institute of Aeronautics and Astronautics, Inc. No copyright is asserted in the United States under Title 17, U.S. Code. The U.S. Government has a royalty-free license to exercise all rights under the copyright claimed herein for Governmental purposes. All other rights are reserved by the copyright owner.
$C_{q_{M R}}$

multiple-region suction coefficient,

$$
\frac{\sum_{R=i}^{f} C_{q_{R}} A_{R}}{\sum_{R=i}^{f} A_{R}}
$$

final suction region

FCV flow control valve

FS fuselage station

$H_{p} \quad$ pressure altitude, $\mathrm{km}(\mathrm{kft})$

HSCT High-Speed Civil Transport

$i$

$\mathrm{L}$ initial suction region laminar flow

LSHF lower-surface hot film

LT laminar flow with turbulent bursts

$M \quad$ Mach number

$m_{\text {flow }} \quad$ mass flow for each unit area

$R \quad$ suction region

$\mathrm{T}$

turbulent flow

TL turbulent flow with laminar bursts

TR peak transition flow

$U \quad$ velocity

V voltage, volts

$x / c$

chord-wise distance from the leading edge

chord location (nondimensional)

$\alpha \quad$ angle of attack, deg

$\beta \quad$ angle of sideslip, deg

$\rho \quad$ density

$\infty \quad$ free-stream condition 


\section{INTRODUCTION}

Laminar flow control has long been considered as a potentially viable technique for increasing aircraft performance. Previous studies have demonstrated that laminar flow control could reduce takeoff gross weight, mission fuel burn, structural temperatures, emissions, and sonic boom. ${ }^{1-3}$ The NASA High-Speed Research program has obtained data to quantify the benefits of this technology.

In response to interest in implementing this technology on the proposed High-Speed Civil Transport (HSCT), NASA initiated the F-16XL Supersonic Laminar Flow Control (SLFC) flight program. This research project used two prototype F-16XL aircraft. The F-16XL-1 project, using active (with suction) and passive (without suction) gloves on the left wing, demonstrated that laminar flow can be achieved on a highly swept-wing configuration at supersonic speeds. ${ }^{4}$ Pressure-distribution and transition data were obtained for a Mach range of 1.2-1.7 and an altitude range of $10,668-16,764 \mathrm{~m}(35,000-55,000 \mathrm{ft})$. The results show that large regions of laminar flow can be achieved when active laminar flow control is used. ${ }^{5}$

Using a passive wing glove on the right wing of the aircraft, the first phase of the F-16XL-2 project studied the effects of attachment line, leading-edge radius, and very high Reynolds number on the boundary layer. ${ }^{4} \mathrm{~A}$ primary goal of the passive glove experiment was to obtain detailed surface pressure-distribution data in the leading-edge region. These data were obtained for a Mach range of 1.4-2.0 and an altitude range of 13,716$15,240 \mathrm{~m}(45,000-50,000 \mathrm{ft}){ }^{6}$

This paper discusses the second phase of the F-16XL-2 project, in which an active glove flown on the left wing at supersonic, high-altitude flight conditions demonstrated the feasibility of laminar flow control for the proposed $\mathrm{HSCT}^{7}{ }^{7}$ Unlike the active glove used on the F-16XL-1 airplane, this glove was optimized for laminar flow and had variable hole spacing. Team members from the NASA Dryden Flight Research Center (Edwards, California), NASA Langley Research Center (Hampton, Virginia), Boeing Commercial Airplane Group (Seattle, Washington), McDonnell Douglas Corporation (Long Beach, California) and Rockwell International (Seal Beach, California) supported this project.

The F-16XL-2 airplane partly was chosen as the flight research vehicle because its planform (70-deg inboard wing sweep), maximum speed (Mach 2.0), and maximum altitude $(16,764 \mathrm{~m}$ or $55,000 \mathrm{ft})$ are similar to the planform, desired cruise speed (Mach 2.4), and cruise altitude $(18,288 \mathrm{~m}$ or $60,000 \mathrm{ft})$ of the HSCT. Although the F-16XL aircraft has similar properties to the proposed HSCT, some peculiarities in this experiment are specific to the F-16XL-2 airplane and would not be of concern if the HSCT uses this technology.

The necessary F-16XL-2 modifications included the installation of a titanium glove on the left wing of the aircraft, the extension of the leading-edge region to continue the 70-deg inboard wing sweep into the fuselage (fig. 1), and the installation of a suction pump to act as the suction source for the experiment. The objectives of the flight experiment were to achieve laminar flow at $0.50-0.60$ chord location $(x / c)$ on a highly swept wing at supersonic speeds and to validate the tools used in the design of this experiment.

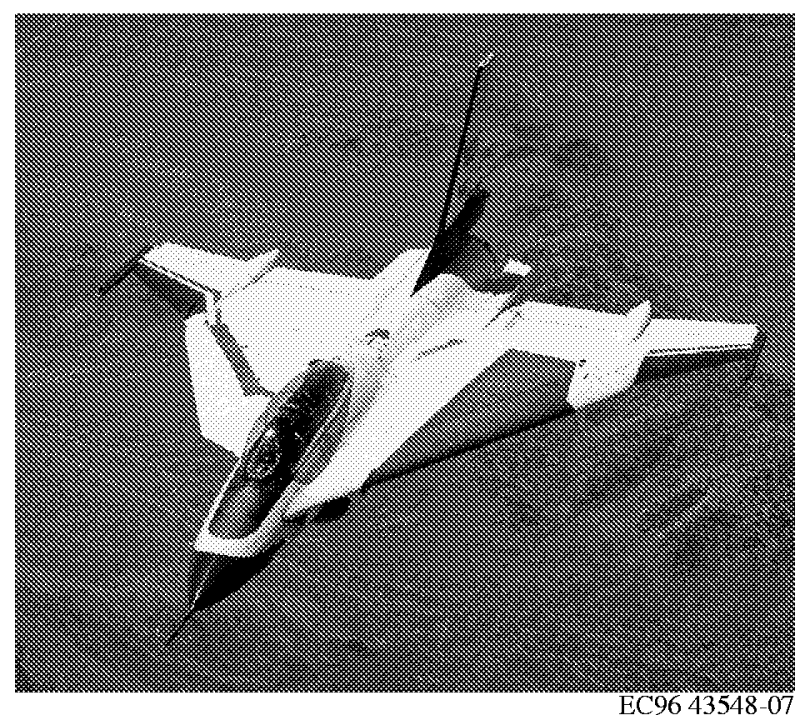

Figure 1. The F-16XL-2 dual-place aircraft with suction glove installed on left wing.

NASA Dryden conducted 45 flights in support of this experiment. This paper discusses research variables that directly impacted the ability to obtain laminar flow and the techniques used to correct for these variables in flight. The variables included flight conditions, suction, and unique F-16XL-2 shock systems.

Note that use of trade names or names of manufacturers in this document does not constitute an official endorsement of such products or manufacturers, either expressed or implied, by the National Aeronautics and Space Administration. 


\section{AIRCRAFT DESCRIPTION}

The F-16XL-2 aircraft was selected for this experiment because of its similarity to the proposed HSCT in both its planform and maximum attainable flight conditions. The F-16XL aircraft has a doubledelta-wing configuration and is a modification of the standard F-16 airplane. The wing leading-edge sweep is $70^{\circ}$ and $50^{\circ}$ in the inboard and outboard regions, respectively.

The F-16XL-2 airplane was the second F-16 airplane modified by General Dynamics (Fort Worth, Texas). The two-seat aircraft is capable of cruising at a speed of Mach 2.0 and an altitude of $16,764 \mathrm{~m}(55,000 \mathrm{ft})$ when powered by the F110-GE-129 engine (General Electric, Evandale, Ohio). Figure 1 shows the left wing of the aircraft modified with a laminar flow control glove.

\section{EXPERIMENT DESCRIPTION}

Several components, discussed in the following sections, were required to ensure a successful F-16XL-2 laminar flow experiment. These components included the design flight conditions and pressure distribution, a wing glove, a suction system, shock fences, and a turbulence diverter.

\section{Design Flight Conditions}

The design point of the experiment was selected based on computational fluid dynamics and previous transition flight experiments. The design point, a speed of Mach 1.9 at an altitude of $15,240 \mathrm{~m}(50,000 \mathrm{ft})$, was still within the F-16XL-2 flight envelope after the airplane was modified for this experiment.

Depending on drag and engine performance, Mach numbers and altitudes higher than the design point could be achieved. The calculated Reynolds number at the design condition was $2.25 \times 10^{6}$, which was a function of the local temperature at altitude and varied for each flight. The design angles of attack and sideslip were $3.3^{\circ}$ and $0^{\circ}$, respectively.

\section{Design Pressure Distribution}

The design pressure distribution over the wing included the components required to minimize transition-causing disturbances. The steep leading-edge acceleration to the wing upper surface allowed a rapid progression through the region of crossflow. The acceleration was followed by a gradual, favorable pressure gradient that acted to stabilize TollmienSchlichting disturbances. Predictions further indicated that the lack of span-wise gradients in the design pressure distribution allowed for nearly unswept isobars on the upper surface at the design angle of attack. ${ }^{8}$

Predictions indicated that although the design pressure distribution was instrumental in obtaining laminar flow, suction was required to obtain extensive laminar flow on the highly swept wing. To obtain the necessary suction, extensive F-16XL-2 modifications were made that were unique to the experiment.

\section{Wing Glove}

A perforated wing glove was installed on the left wing of the F-16XL-2 airplane. This glove and its fairing were designed by Boeing using a "constrained direct iterative surface curvature" inverse design method (developed by NASA Langley) coupled with a three-dimensional, thin-layer Navier-Stokes flow solver. ${ }^{8}$ The glove, which Boeing also fabricated, was constructed of 1.016-mm-thick (0.040-in.-thick) titanium perforated with more than twelve million laserdrilled holes. These holes nominally were $0.0635 \mathrm{~mm}$ $(0.0025 \mathrm{in}$.) in diameter and had a varied spacing range of $0.254-1.397 \mathrm{~mm}(0.010-0.055 \mathrm{in}$.), depending on the required suction porosity. ${ }^{7}$ The conically shaped holes provided the perforated surface through which the boundary-layer instabilities were removed.

The glove was a shell that encompassed the left wing, not a replacement to the original wing. The suction panel had a $12.70-\mathrm{mm}(0.50-$ in. $)$ leading-edge radius and extended $5.18 \mathrm{~m}(17.00 \mathrm{ft})$ along the leading edge and back to $0.60 x / c$. The suction panel was bounded by the apex, an aluminum substructure with a carbon-fiber cover; and a carbon-fiber passive fairing that blended the panel with the existing wing contour. Support structures (apex region) were added that continued the 70-deg swept wing into the fuselage (fig. 2). With these modifications, the F-16XL-2 left wing better modeled the proposed HSCT wing.

\section{$\underline{\text { Suction System }}$}

The design suction distribution was derived by Boeing using linear, boundary-layer-stability-theory calculations. This analysis was correlated with windtunnel and flight transition data and was used to establish the criteria for the maximum and minimum suction levels. ${ }^{8}$

A suction control system was designed to achieve the design suction distribution as closely as possible while applying suction to the panel surface at different levels and locations. Figure 3 shows a schematic of the suction system. Suction was provided for this system by a modified Boeing 707 cabin air-pressurization 


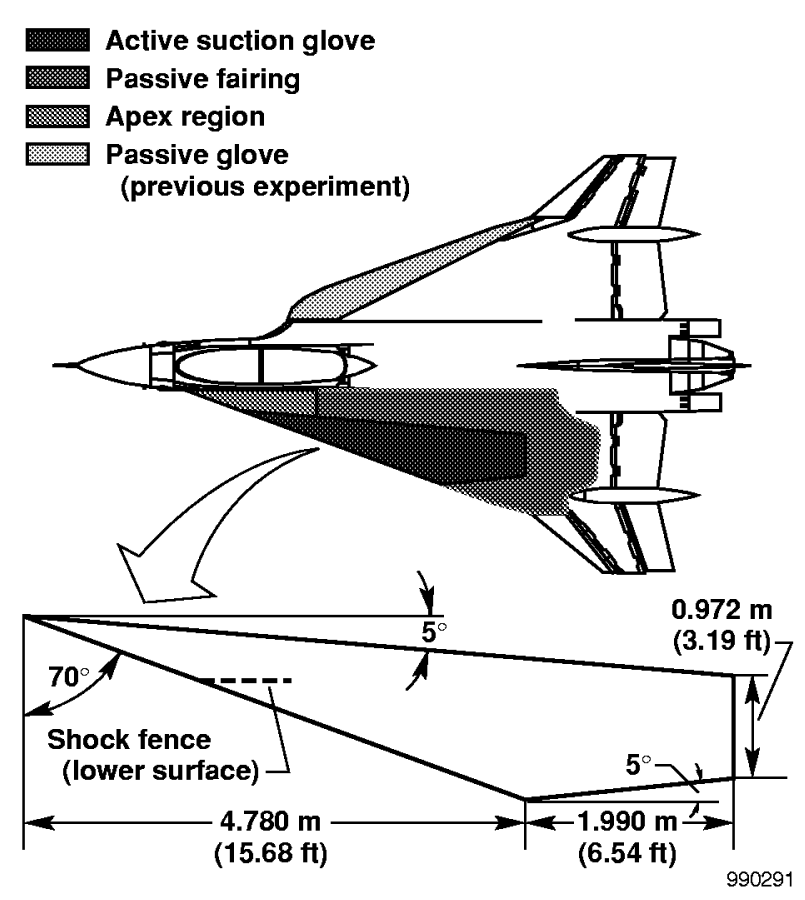

Figure 2. Aircraft configuration.

turbocompressor located in the ammunition drum bay. The rate of air drawn through the suction-panel holes was measured by mass flow sensors and controlled by butterfly flow control valves (FCVs), which then led into a common chamber, the plenum. From the plenum, air passed through a large duct where the master FCV was located. When insufficient quantities of air were drawn through the master FCV, a surge valve opened to provide supplemental air to the turbocompressor, which was nominally driven by engine-bleed air. All air exiting the turbocompressor was then vented overboard, on the right side of the aircraft.

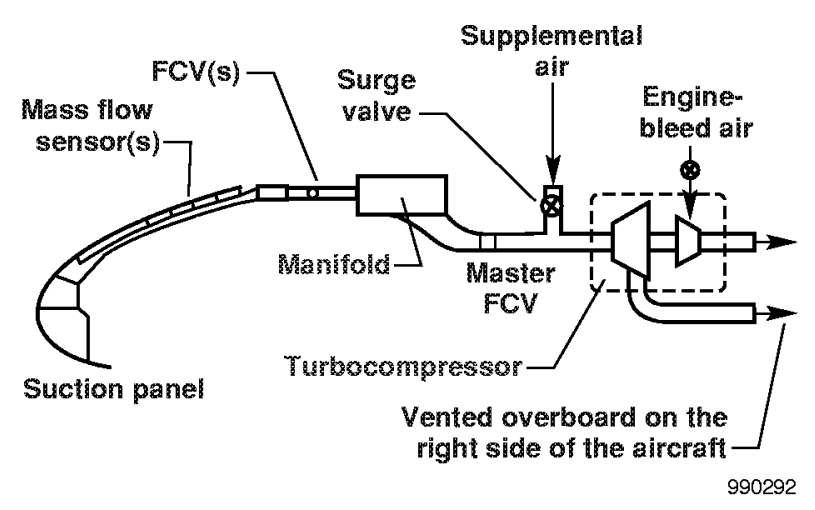

Figure 3. Suction system schematic.
The suction panel was divided into 20 regions, 13 of which were located in the leading edge. Three flutes, compartments created by fiberglass dividers, provided suction to those regions located in the leading edge. Figure 4 shows the four suction regions fed by each flute. Each of the 20 regions had its own mass flow sensor and FCV. A setting of $0^{\circ}$ represented a closed valve; a setting of $90^{\circ}$ represented a completely open valve.

The suction control system controlled the master FCV and the $20 \mathrm{FCVs}$ through a computer onboard the aircraft. In real time, this computer interfaced the uplinked command signal from the control room with the FCVs and set the suction levels for the 20 regions. The FCVs in each region were individually controlled, which allowed for different suction settings within each region. This system permitted several suction distributions to be studied during a given flight.

\section{Shock Fences}

Because of the engine-inlet configuration of the F-16XL-2 airplane, some concern existed that inletgenerated shocks could impact the leading edge of the glove, reducing the possibility of obtaining laminar flow in the affected region. To address this concern, a 50.8-cm-tall (20.0-in-tall), vertical shock fence, constructed of aluminum, was installed on the lower surface of the left wing at butt line $(B L) 165 .^{7}$ The shock fence was mounted at a weapons ordnance hard-

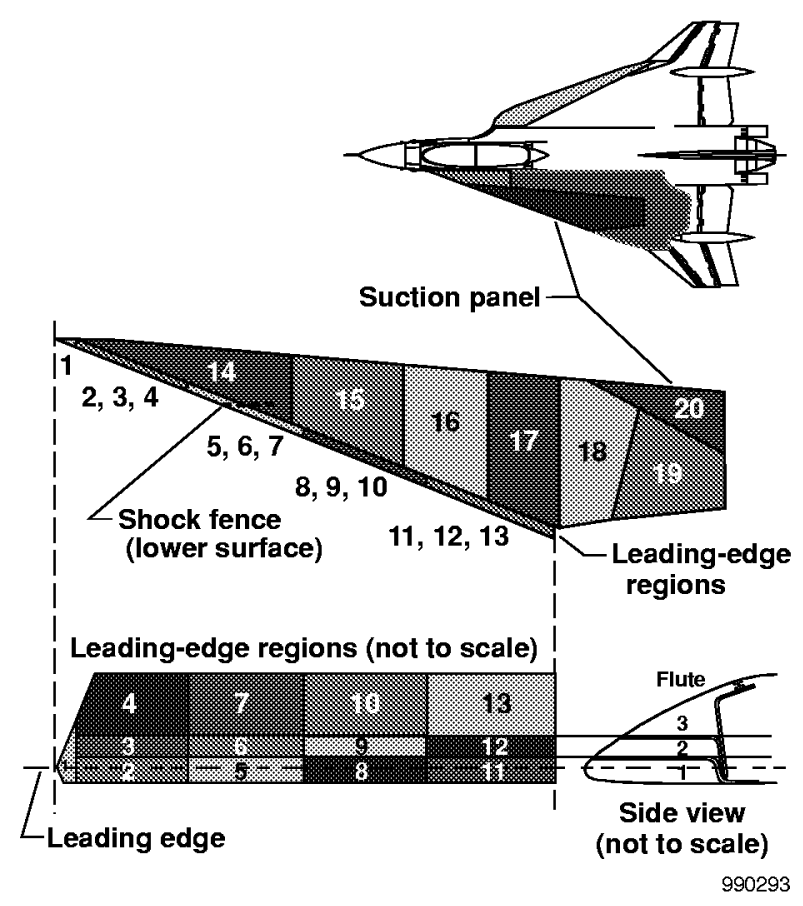

Figure 4. Suction-panel regions. 
attachment point to block the potential engine-inlet shocks.

The two shock-fence designs flown during the experiment were designated by the sweep angle the shock-fence leading edge made with the vertical. The first fence flown was the 60 -deg shock fence. This fence was based on a 25.4-cm-tall (10.0-in.- tall) design flown during the previous phase of the F-16XL-2 laminar flow project. ${ }^{6}$ The 60 -deg shock fence was flown on 19 flights of this experiment. The second fence flown was the 10-deg shock fence installed for 24 of the research flights. The 10-deg sweep of this fence yielded a supersonic leading edge. Two flights were flown without either shock fence installed.

\section{Turbulence Diverter}

A turbulence diverter was installed inboard of the suction panel at the leading edge. ${ }^{7}$ The turbulence diverter was a passive device used to create a laminar attachment line on the glove. The diverter consisted of a narrow (19.80-mm or 0.78-in. width) longitudinal slot on the leading edge just inboard of the suction panel. This slot allowed the turbulent attachment-line boundary layer flowing outboard from the passive-fairing leading edge to be swept away and a new laminar attachmentline boundary layer to be formed on the inboard leading edge of the panel.

Three diverter configurations were flown during the previous phase of the F-16XL-2 laminar flow project. The design used for this experiment was determined to be the most effective.

\section{INSTRUMENTATION}

Airdata parameters were measured using a flight test noseboom (fig. 1) designed to measure airspeed and flow angles. In addition to the dual flow-angle vanes used to measure the angles of attack and sideslip, the noseboom also provided measurements of total and static pressure. Angle-of-attack calibration data were obtained during the previous phase of the F-16XL-2 laminar flow experiment. Flow-angle accuracies were $\pm 0.3^{\circ}$ and $\pm 0.5^{\circ}$ for the angles of attack and sideslip, respectively.

The aircraft was also instrumented to measure total temperature, Euler angles, accelerations, and controlsurface positions. The wing glove instrumentation consisted of pressure orifices, thermocouples, microphones, mass flow sensors, and hot-film anemometers. This paper primarily focuses on the data obtained from the hot-film anemometers.

\section{Pressure Taps}

Both surface and internal pressure measurements were obtained during the experiment. Of the 454 surface pressure taps, 200 were located on the active suction panel, 113 of which were in the leading-edge region.

The remaining 254 surface pressure taps were located on the apex and passive fairing, surrounding the suction panel. These taps were flush-mounted pressure orifices with an internal diameter of $1.587 \mathrm{~mm}(0.0625 \mathrm{in}$.) The 72 internal pressure taps were used to monitor the pressure within the suction flutes.

\section{Mass Flow Sensors}

Twenty mass flow sensors were inserted in the ducts between the suction-panel surface and the FCVs. These sensors, designed by Kurz Instruments Inc. (Monterey, California), were used to measure the suction flow rate in each region. The sensors were based on a Kurz Instruments thermal convective single-point insertion "CD" TM mass velocity sensor and consisted of a glasscoated platinum wire over ceramic sealed with epoxy.

The mass flow sensors had an accuracy of \pm 3 percent of the reading. Each sensor and region valve assembly used to correlate valve position with mass flow was laboratory-calibrated at NASA Langley.

\section{$\underline{\text { Hot-Film Anemometers }}$}

Hot-film sensors with temperature-compensated anemometer systems were used on or around the suction panel on both the upper and lower surfaces. Hot-film sensors of this type have been used on high-performance aircraft in several experiments at NASA Dryden. The sensors were mounted such that their active elements were nearly perpendicular to the airflow, with the temperature elements adjacent and slightly aft of the hot-film sensors to avoid possible flow disturbance over the active elements of the hot-film sensors. The anemometer system compensates for the local stagnation temperature, which allows the sensors to operate in conditions where large speed and altitude variations occur. $^{9}$

Twenty-four hot-film sensors were mounted directly to the titanium surface on the edge of the active suction region on the wing upper surface. The amount of hot films on the active suction surface varied from 0 for the first 8 flights to 31 for the final flights. The location of these hot films varied as different areas of the suction panel were investigated. The desire to mount hot films to the active suction surface generated some concern about 
residue blocking the suction-panel holes. As a result, the sensors were directly mounted not to the surface, but instead to polyester tape that left no residue and was rated for high temperatures and dynamic pressures. Before this experiment began, speed and temperature tests were performed both in flight and in the laboratory to verify that the tape could be used in this manner.

Lower-surface hot films placed near the leading edge were used to identify the span-wise extent of laminar flow at the attachment line. Although the number of usable lower-surface hot films was limited to 15 , the location and number of these sensors also varied throughout the flight phase. Initially, 14 lower-surface hot films were used, the first of which was mounted to the carbon-fiber panel just forward of the turbulence diverter. The other 13 were mounted directly to the titanium surface on the edge of the suction-panel regions. Figure 5 shows the 146 hot-film locations studied throughout the flight phase. The number of hotfilm anemometry cards available in the instrumentation system limited the number of recorded hot films to 50 preflight-determined hot films.

\section{Data Recording}

All instrumentation data were telemetered to a ground station in real time during the research flights and recorded. The airdata and aircraft parameters were measured at $50 \mathrm{samples} / \mathrm{sec}$. The research pressure data were obtained at 12.5 samples/sec. Mass flow data were obtained at 60 samples/sec. The telemetered hot-film data were acquired at 100 samples/sec. Hot-film data

\footnotetext{
- Hot-film sensor

----- Suction region boundary

- - Suction-panel boundary

- Titanium panel edge
}

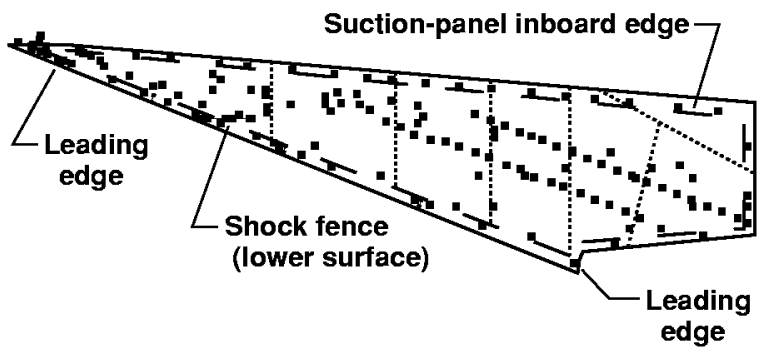

Upper-surface hot films on suction-panel surface = 102 Upper-surface hot films on suction-panel edge $=\mathbf{2 4}$ Lower-surface hot films $=\mathbf{2 0}$ Total number of hot-film locations = 146

Figure 5. Hot-film locations studied. were also recorded on a 14-track magnetic tape drive using frequency modulation and constant bandwidth. These high-frequency data were recorded at 2 and $10 \mathrm{kHz}$ during the program; however, the results presented in this paper were derived from the telemetered data because transition was easily observed at that frequency. Hot-film signals were measured in volts and displayed in the control room, which allowed decisions regarding flight-maneuver quality to be made in real time

The hot-film sensor signal used in this experiment had both direct-current (steady-state) and alternating-current (dynamic) components. In previous NASA Dryden experiments, these components were separated and recorded as two signals. ${ }^{10}$ Boundary-layer state classification requires both components to obtain the best results. For this experiment, the two components were recorded as one signal.

Figure 6 shows a hot-film signal under a laminar boundary layer that has turbulent bursts bounded by a signal from a turbulent boundary layer at the beginning and the end. The top curve shows the combined signals; the second curve shows the direct-current (steady-state) component of the signal; and the bottom curve shows the alternating-current (dynamic) component of the signal. This combination signal eliminated some confusion and made boundary-layer state classification an easier process.

\section{Interpretation of Hot-Film Signals}

Hot-film sensors were used to determine the boundary-layer state. Figure 7 shows typical hot-film

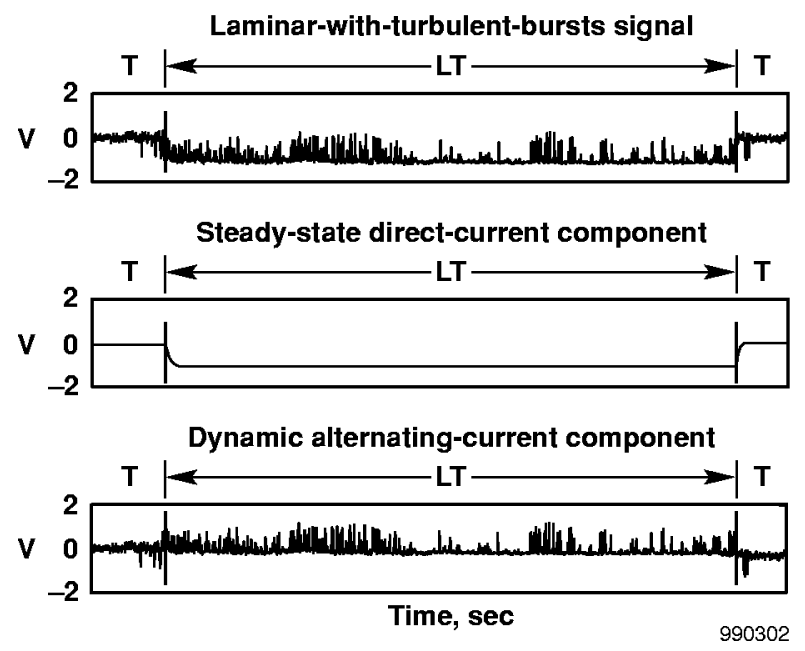

Figure 6. Hot-film signal components. 

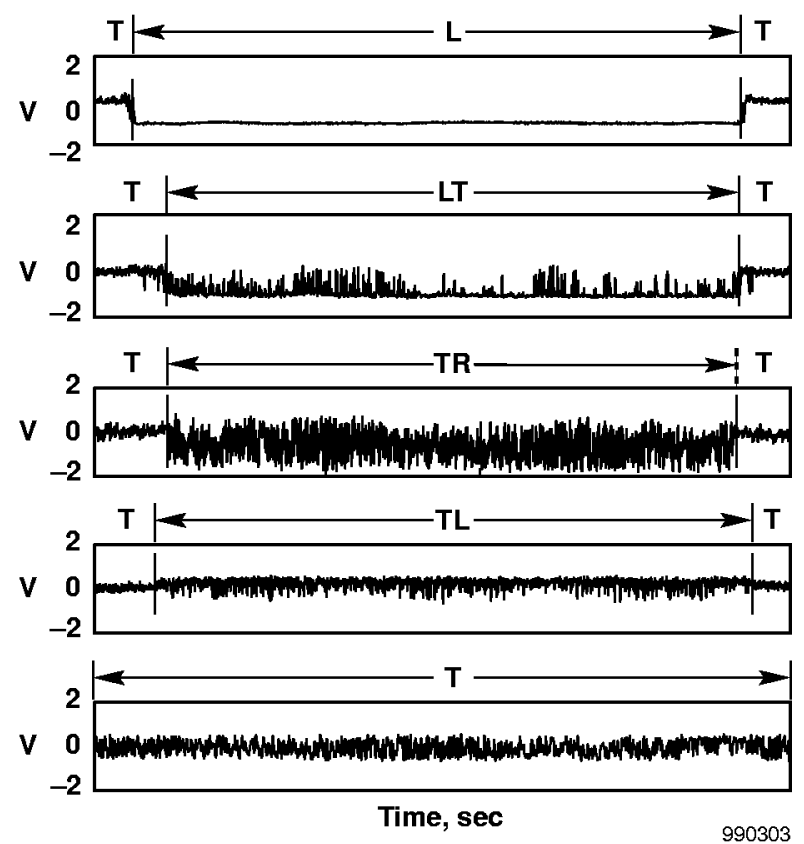

Figure 7. Hot-film signal classifications.

signals and their boundary-layer state designation. The dynamic portion of the hot-film signal was "quieter" for laminar flow than for turbulent flow because the temperature-compensated hot-film sensors required less voltage input to keep the temperature constant for laminar flow. Laminar flow required less voltage because of little mixing in the boundary layer; therefore, less convective heat transfer away from the sensor existed than for turbulent flow. Consequently, the signal had a low amplitude. Conversely, for turbulent flow where heat-transfer rates increase and rapidly fluctuate because of large mixing in the boundary layer, higher voltage was required and the signals had a higher amplitude.

The steady-state portion of the hot-film signal was characterized by a voltage offset. This offset was a lower voltage for hot films in areas of laminar flow as compared to turbulent flow. High-amplitude spikes were an indication of transitional flow. Spikes in the direction of positive voltage indicated a mostly laminar signal with turbulent bursts. Spikes in the direction of negative voltage indicated a mostly turbulent signal with laminar bursts. Peak transition was indicated by the maximum occurrence of high-amplitude spikes. ${ }^{10,11}$

\section{TEST CONDITIONS}

Data were obtained throughout each research flight; however, the results presented in this paper primarily were obtained at flight conditions of Mach 2 at altitudes ranging from $15,240 \mathrm{~m}$ to $16,764 \mathrm{~m}(50,000 \mathrm{ft}$ to $55,000 \mathrm{ft}$ ); angles of attack ranging from $2.0^{\circ}$ to $4.0^{\circ}$; and angles of sideslip of either $0.0^{\circ}$ or $1.5^{\circ}$ nose right. Several disturbances occurred, which will be discussed in the "Results" section, that led to the maneuvers primarily being conducted at these flight conditions instead of the design conditions of Mach 1.9, an altitude of $15,240 \mathrm{~m}(50,000 \mathrm{ft}), 3.3^{\circ}$ angle of attack, and $0.0^{\circ}$ angle of sideslip.

The design conditions were determined from previous flight results and analysis of computational fluid dynamics results. The desired angles of attack and sideslip were based on the cruise conditions of the HSCT $\left(3.5^{\circ}\right.$ and $0.0^{\circ}$ angles of attack and sideslip, respectively). The maneuvers typically performed were steady-state pushovers to a predesignated angle of attack. These pushovers were performed with and without sideslip and were approximately $10 \mathrm{sec}$ in duration.

\section{RESULTS}

The flight test results presented consist primarily of boundary-layer transition data obtained from hot-film sensors. In the following sections, attachment-line flight condition and shock-fence effects, suction effects, and the extent of laminar flow obtained are discussed.

\section{Attachment-Line Flight Condition and Shock-Fence Effects}

Key parameters in laminar flow experiments are Reynolds number, angle of attack, and angle of sideslip. Figure 8 shows conditions where a laminar attachment line was obtained as a function of angles of attack and sideslip. The data were acquired at a Mach number range of $1.9-2.0$ and an altitude range of 15,301$16,886 \mathrm{~m} \quad(50,200-55,400 \mathrm{ft})$. The symbols (fig. 8) represent the test points where all lower-surface hot films were laminar, indicating a laminar attachment line.

The data are further defined by shock-fence configuration. Triangles represent data from flights when the 60-deg shock fence was installed, and circles represent the 10-deg shock-fence data (fig. 8). The reason for two shock-fence designs was based on their influence on the attachment line. A completely laminar attachment line was not attainable without a shock fence installed because of shocks emanating from the engine inlet. ${ }^{7}$ During the two flights without a shock fence installed, $2.9^{\circ}$ was the maximum angle of attack for which the lower-surface hot films inboard of the 


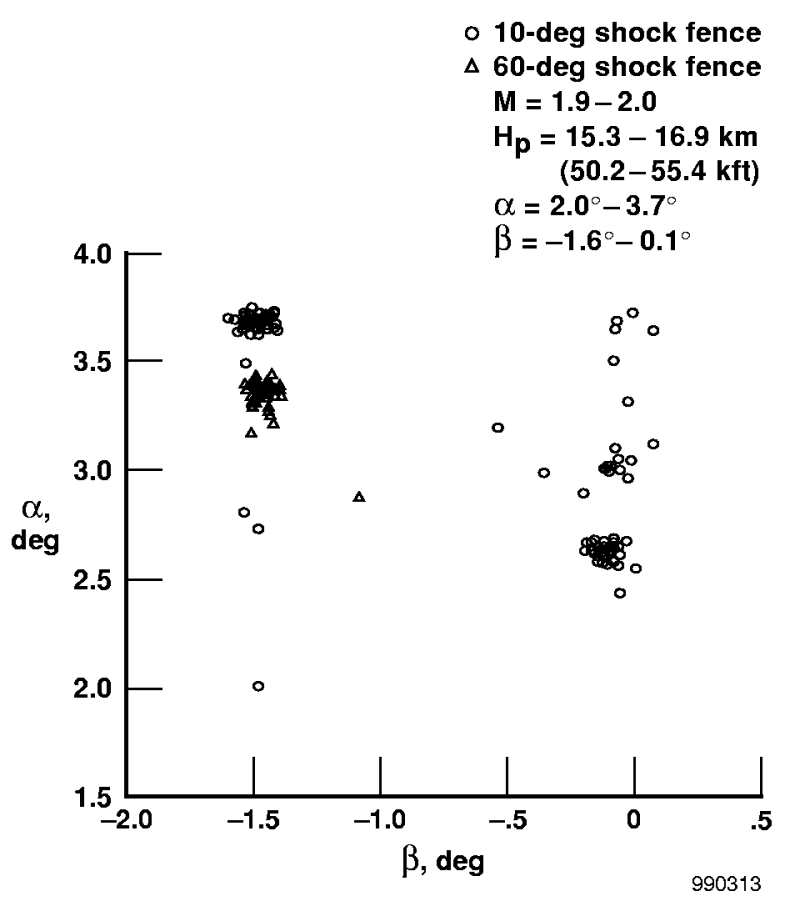

Figure 8. Angle-of-attack and -sideslip test conditions under which a laminar attachment line was obtained.

shock-fence location were laminar. The outboard lowersurface hot films were not expected to be laminar because no shock fence was installed to keep the engine-inlet shock from impacting the attachment line.

The best repeatable laminar flow results achieved at a desirable angle of attack occurred at $3.7^{\circ}$ angle of attack for a unit Reynolds number of $7.32 \times 10^{6} / \mathrm{m}$ $\left(2.23 \times 10^{6} / \mathrm{ft}\right)$. During these research flights, a unit Reynolds number of $7.32 \times 10^{6} / \mathrm{m}\left(2.23 \times 10^{6} / \mathrm{ft}\right)$ was most often attained at a speed of Mach 2.0 and an altitude of $16,154 \mathrm{~m}(53,000 \mathrm{ft})$. The attachment-line laminar flow results were very sensitive to angles of attack and sideslip. Investigation with the 10-deg shock fence installed proved that a laminar attachment line could be achieved for angles of attack as high as $3.7^{\circ}$. Figure 8 shows angles of attack and sideslip plotted for this test condition. Both positive (nose left) and negative angles of sideslip were investigated. A laminar attachment line could not be achieved for positive angles of sideslip. Although a laminar attachment line could be obtained for $0^{\circ}$ angle of sideslip, the most successful laminar flow results repeatedly were obtained by "unsweeping" the left wing to $-1.5^{\circ}$ angle of sideslip.

\section{Suction Effects on Transition}

To achieve laminar flow, the experiment used FCVs in the ducts to actively control suction on the perforated suction glove. Obtaining the optimum suction distribution over the panel was extremely important and challenging. Figure 9 shows the design suction distribution at Mach 1.9 and an altitude of $15,240 \mathrm{~m}$ $(50,000 \mathrm{ft})$. Figure 9 also shows a flight suction distribution that repeatedly yielded successful laminar flow results at Mach 2.0 and an altitude of $16,764 \mathrm{~m}$ $(55,000 \mathrm{ft})$. The flight suction values in flute 1 represent the laminar attachment-line, flight-determined optimum suction level. A laminar attachment line could not be obtained for suction coefficient values in excess of these values, which were usually less than design in the attachment-line regions.

Evidence that the design levels may have been too high in the attachment-line regions was obtained when the suction system was turned off. Because the suction system usually was not turned on until the aircraft was nearing the flight test conditions, time existed to observe the behavior of the hot films with the suction off. The lower-surface hot films located span-wise between the turbulence diverter and the shock fence were often laminar without suction at altitudes and Mach numbers ranging from 13,716 to $15,240 \mathrm{~m}$ ( 45,000 to $50,000 \mathrm{ft}$ ) and 1.69 to 1.93 , respectively. Figure 10 shows examples

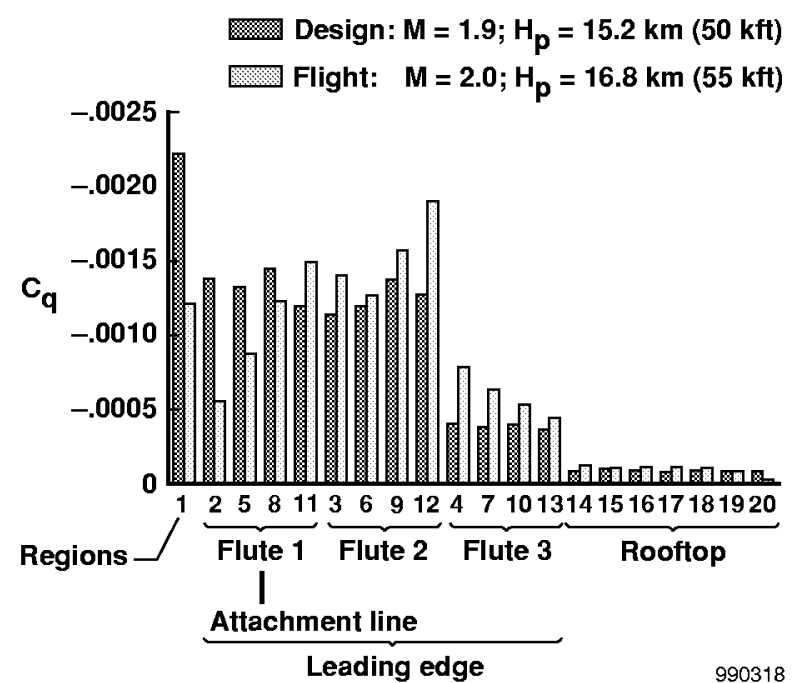

Figure 9. Suction distribution. 

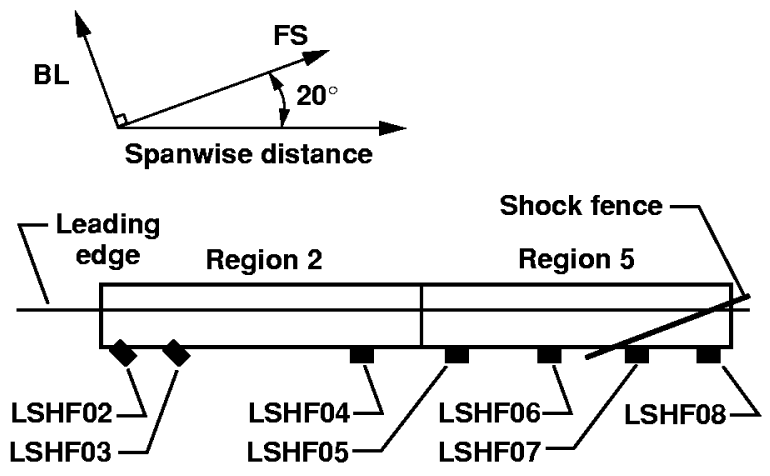

Lower surface hot films

\begin{tabular}{|c|c|c|c|c|c|c|c|c|c|c|}
\hline & & & & \multicolumn{7}{|c|}{ Lower surface hot films } \\
\hline M & $\begin{array}{c}\mathrm{H}_{\mathrm{p}} \\
\mathrm{km}(\mathbf{k f t})\end{array}$ & $\begin{array}{c}\mathrm{Re}, \\
\mathrm{mil} / \mathrm{m} \text { (mil/ft) }\end{array}$ & $\begin{array}{c}\alpha, \\
\text { deg }\end{array}$ & 2 & 3 & 4 & 5 & 6 & 7 & 8 \\
\hline 1.690 & $15.4(50.5)$ & $6.46(1.97)$ & 4.24 & $\mathbf{L}$ & L & L & $\mathbf{L}$ & $T$ & $\mathbf{T}$ & $\bar{T}$ \\
\hline 1.807 & $15.6(50.7)$ & $6.96(2.12)$ & 3.96 & L & L & L & L & $T$ & T & $\begin{array}{lll}T \\
\end{array}$ \\
\hline 1.861 & $15.4(50.4)$ & $7.22(2.20)$ & 3.96 & LT & L & L & LT & L & $T$ & $\mathbf{T}$ \\
\hline 1.898 & $15.1(49.7)$ & $7.94(2.42)$ & 3.24 & LT & L & L & LT & L & T & $\mathbf{T}$ \\
\hline 1.901 & $13.7(45.1)$ & $9.22(2.81)$ & 3.13 & L & L & L & LT & L & $\mathbf{T}$ & $\mathbf{T}$ \\
\hline 1.933 & $15.6(50.7)$ & $7.41(2.26)$ & 3.95 & $\mathbf{L}$ & L & L & LT & $T$ & $\mathbf{T}$ & $\begin{array}{lll} \\
\end{array}$ \\
\hline
\end{tabular}

Figure 10. Lower-surface hot films without suction.

of this phenomenon. These sensors became turbulent when design suction was turned on because of too much suction in the attachment-line regions. However, preflight predictions had shown the design suction level necessary to overcome the leading-edge pressure disturbance from the inlet shock. This need for lowerthan-design suction occurred only on the attachment line. In fact, suction in the remaining leading-edge regions was set at levels higher than design (fig. 9) to compensate for the limited levels in the attachment-line regions. ${ }^{8}$

Figure 11 shows examples of the effectiveness of these and other suction settings in flight at a speed of Mach 2.0 and altitudes ranging from 16,154 to $16,764 \mathrm{~m}(53,000$ to $55,000 \mathrm{ft}$ ). The data are from the wing glove with the 10-deg shock fence installed and from hot-film sensors indicating the boundary-layer state for a specific suction distribution. The comparison plots (fig. 11) were compiled from several flights, and the hot-film layout varied from flight to flight. The boundary-layer state in a specific region varied as suction changed within that region.

In the attachment-line regions, the FCVs were all set to the same flight values as those shown in figure 9. Any disparity in the mass flow (that is, the suction coefficient) for constant valve settings were caused by changes in flight condition. Throughout the flight experiment, the suction valve in region 20 was closed and no hot films were placed on the suction-panel surface in that area, because laminar flow was not expected.

The leading-edge suction values (fig. 11) represent the flight-determined optimum suction settings for a laminar attachment line. The large steps in suction in the rooftop regions (figs. 11(a)-(c)) demonstrate the necessity for high suction in these regions. The small FCV angles in the rooftop regions (fig. 11(a)) yielded mostly turbulent hot-film signals, but the hot films in figure 11(b) indicate more laminar signals for a $20-\mathrm{deg}$ change in FCV position. The suction distribution shown in figure 11(c) is the same flight distribution shown in figure 9; valves in the rooftop regions are open to $90^{\circ}$. This distribution also yielded a laminar attachment line and laminar flow in the rooftop regions. The turbulent and turbulent-withlaminar-bursts signals in region 15 were caused by the existence of the hot-film sensors mounted forward of the sensors in region 14 .

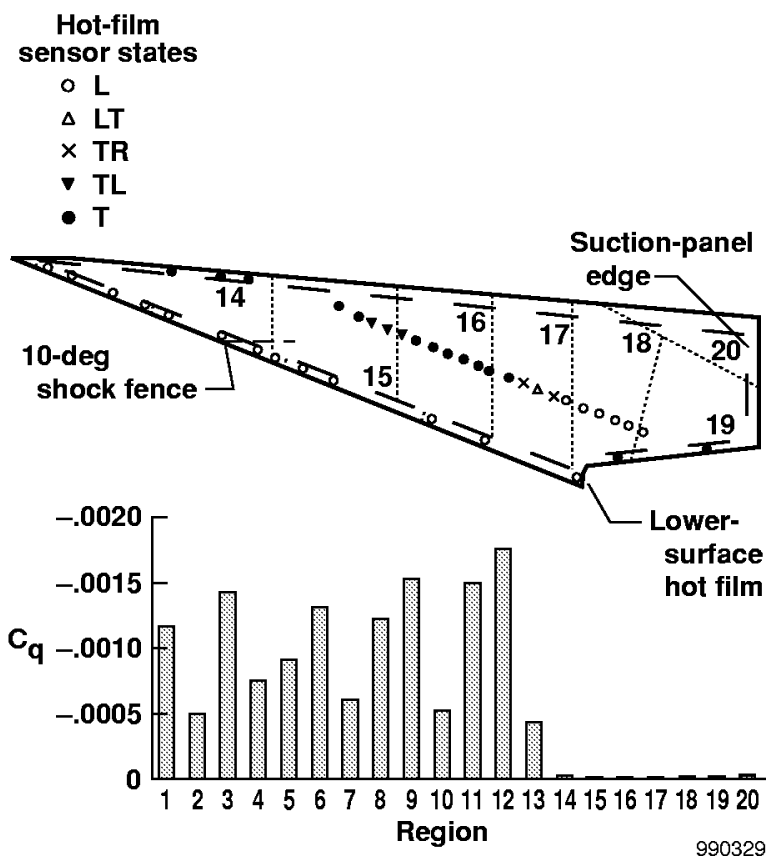

(a) Regions 14-19; FCV angles $=15^{\circ}$.

Figure 11. Rooftop suction effects at Mach 2.0, an altitude of $16,855 \mathrm{~m}(55,300 \mathrm{ft}), 3.7^{\circ}$ angle of attack, and $-1.4^{\circ}$ angle of sideslip. 


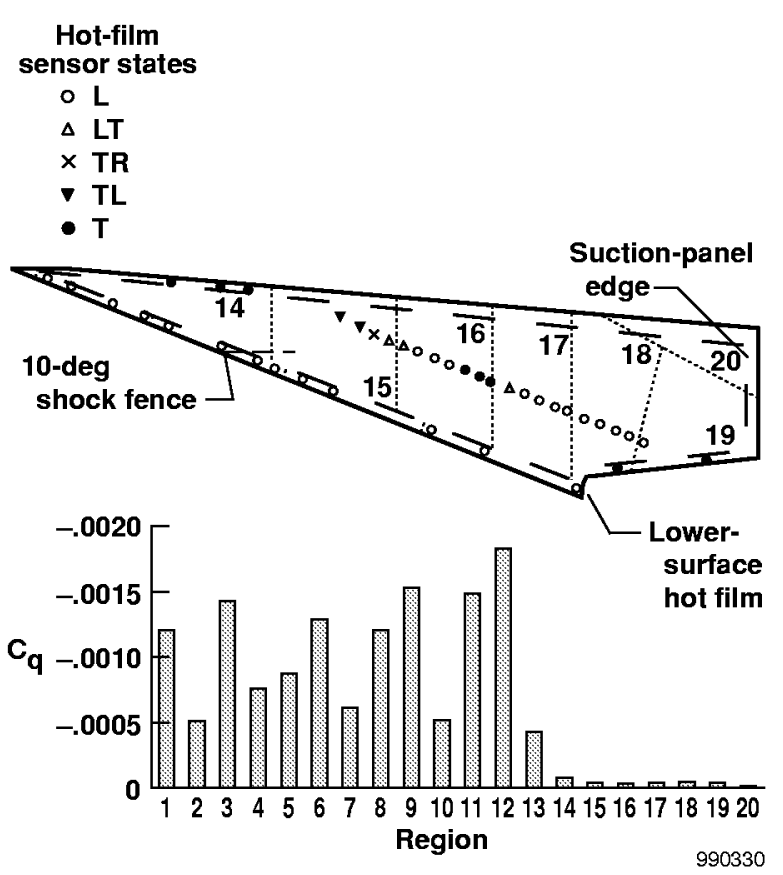

(b) Regions 14-19; FCV angles $=35^{\circ}$.

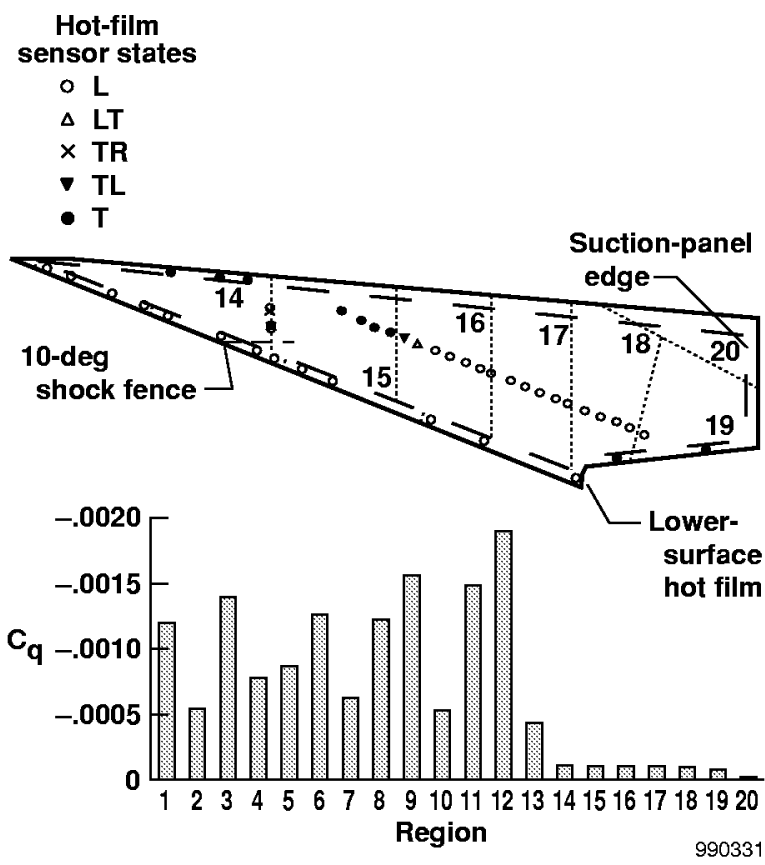

(c) Regions 14-19; FCV angles $=90^{\circ}$.

Figure 11. Concluded.

\section{Extent of Laminar Flow}

When all of the attachment-line variables were taken into account and the suction system had been exercised and its limits understood, the extent of laminar flow could be maximized. Figures 12 and 13 show two cases that document the long runs of laminar flow achieved at Mach 2 during the course of the program. The figures show the wing glove with hot-film sensors that indicate the state of the boundary layer for a specific suction distribution. The shaded area represents the region of laminar flow over the wing glove. In both cases, all the lower-surface hot films were laminar, indicating a laminar attachment line. The suction distribution for each case, including the design suction, is also shown. As in the distribution from figures 9 and 11(c), maximum suction was employed in flutes 2 and 3 and in the rooftop regions, with suction variation occurring only for the attachment-line regions. By using a multiple-region suction coefficient $\left(C_{q_{M R}}\right)$ for flute 1 , a 45.3-percent difference exists with \pm 3 .3-percent error between the flute 1 suction distributions of the two cases. Both of the cases shown were obtained with the 10-deg shock fence installed.

In figure 12 , the laminar flow region is bounded by turbulent and laminar-with-turbulent-bursts hot-film

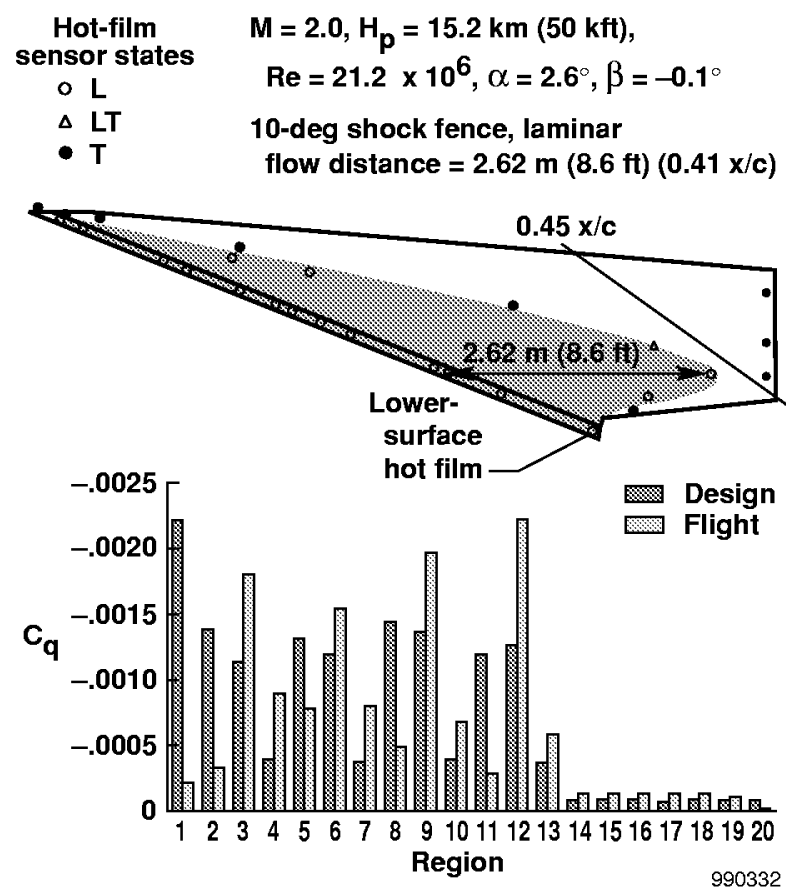

Figure 12. Maximum extent of laminar flow achieved at $15,240 \mathrm{~m}$ or $50,000 \mathrm{ft}$ and $2.6^{\circ}$ angle of attack. 
signals. The hot film furthest aft to indicate laminar flow for this test point was located at $0.41 x / c$, which made the maximum laminar flow distance a minimum of $2.62 \mathrm{~m}$ $(8.60 \mathrm{ft})$. This location corresponds to a Reynolds number of $21.2 \times 10^{6}$ at $2.6^{\circ}$ angle of attack and $0.0^{\circ}$ angle of sideslip. The attachment-line suction distribution was not the flight-determined optimum discussed in the "Suction Effects on Transition Results" subsection. However, a laminar attachment line was still attainable because of the low angle of attack, which was lower than the desired HSCT cruise angle of attack.

Figure 13 shows the laminar flow region bounded by turbulent and transitional hot-film signals. This test point occurred at $3.7^{\circ}$ angle of attack (closer to the desired HSCT cruise angle of attack than those of figure 12), $-1.5^{\circ}$ angle of sideslip, and a Reynolds number of $22.7 \times 10^{6}$. The hot film furthest aft to be laminar was located at $0.46 x / c$, which made the laminar flow distance $3.14 \mathrm{~m}$ (10.30 ft). Except for the very small variation in region 11 , the suction distribution shown is identical to those shown in figures 9 and 11(c).

These long runs of laminar flow were not the only cases. In fact, a very good example of repeatability occurred on the last flight in which 14 test points consistently

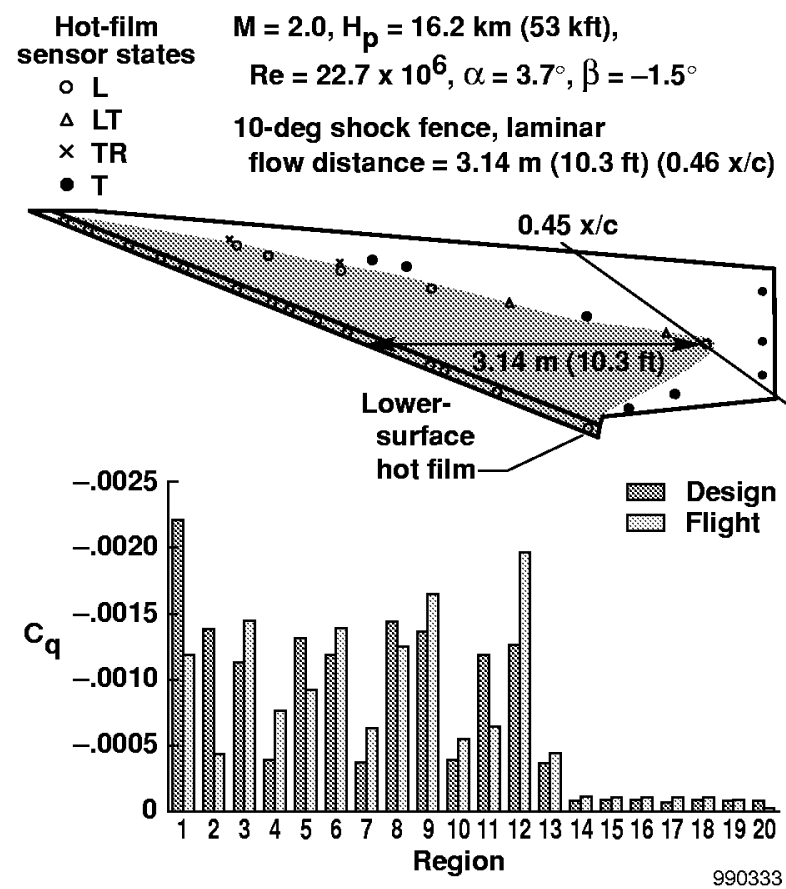

Figure 13. Maximum extent of laminar flow achieved $\left(16,154 \mathrm{~m}\right.$ or $53,000 \mathrm{ft}$ and $3.7^{\circ}$ angle of attack). demonstrated laminar flow as far aft as $0.42 x / c$. All of these cases occurred at Mach 2.0 and an altitude of $16,154 \mathrm{~m}(53,000 \mathrm{ft})$; used the attachment-line flightdetermined optimum suction levels; and had variation occur only in flutes 2 and 3 and in the rooftop regions. Unfortunately, the direct-current level of several hot-film sensors was out of range on that flight, so the actual extent of laminar flow was unknown.

\section{CONCLUDING REMARKS}

A titanium, laminar flow control glove with variable hole spacing has been flown on the left wing of the F-16XL-2 aircraft. Boundary-layer transition data primarily have been obtained on this glove at a speed of Mach 2.0 and altitudes of 16,154 to $16,764 \mathrm{~m}(53,000$ to $55,000 \mathrm{ft})$.

Best results have been obtained at a speed of Mach 2.0 and an altitude of $16,154 \mathrm{~m}(53,000 \mathrm{ft})$ rather than the design Mach number and altitude (Mach 1.9 and 15,240 $\mathrm{m}$ or $50,000 \mathrm{ft}$, respectively). At an angle of attack $\left(3.7^{\circ}\right)$ near the desired cruise angle for the High-Speed Civil Transport (HSCT), laminar flow was obtained to a minimum 0.46 chord location $(x / c)$ corresponding to a Reynolds number of $22.7 \times 10^{6}$. Laminar flow has been consistently obtained to a minimum $0.42 \mathrm{x} / \mathrm{C}$ with the flight-determined optimum suction levels.

Reducing suction levels at the attachment line from the design levels was necessary to obtain a laminar attachment line. However, increasing the suction levels above design on the rest of the panel was required to maximize the laminar flow conditions further aft.

Shocks peculiar to the F-16XL-2 airplane caused some compromises in the experiment. Shocks off the inlet required a shock fence to be installed on the lower surface of the left wing and the airplane to be flown at an angle of sideslip of $1.5^{\circ}$ nose right. These shocks and resulting effects would not be present on an HSCT implementing laminar flow control technology.

\section{REFERENCES}

${ }^{1}$ Powell, A. G., S. Agrawal, and T. R. Lacey, Feasibility and Benefits of Laminar Flow Control on Supersonic Cruise Airplanes, NASA CR-181817, 1989.

${ }^{2}$ Boeing Commercial Airplane Company, Application of Laminar Flow Control to Supersonic Transport Configurations, NASA CR-181917, 1990. 
${ }^{3}$ Pfenninger, Werner and Chandra S. Vemuru, "Design Aspects of Long Range Supersonic LFC Airplanes with Highly Swept Wings," SAE-881397, Oct. 1988.

${ }^{4}$ Anderson, Bianca T. and Marta Bohn-Meyer, Overview of Supersonic Laminar Flow Control Research on the F-16XL Ships 1 and 2, NASA TM-104257, 1992.

${ }^{5}$ Anderson, Bianca T., Bruce H. Rowan, and Stephen F. Landers, F-16XL Supersonic Laminar Flow Control Glove Initial Flight Test Results, NASA TM-104270, 1993.

${ }^{6}$ Landers, Stephen F., John A. Saltzman, and Lisa J. Bjarke, F-16XL Wing Pressure Distributions and Shock Fence Results from Mach 1.4 to Mach 2.0, NASA TM-97-206219, 1997.

${ }^{7}$ Marshall, Laurie A., Boundary-Layer Transition Results From the F-16XL-2 Supersonic Laminar Flow Control Experiment, NASA TM-1999-209013, 1999.
${ }^{8}$ Anders, Scott G. and Michael C. Fischer, F-16XL-2 Supersonic Laminar Flow Control Flight Test Experiment, NASA TP-1999-209683, 1999.

${ }^{9}$ Chiles, Harry R., The Design and Use of a Temperature-Compensated Hot-Film Anemometer System for Boundary-Layer Flow Transition Detection on Supersonic Aircraft, NASA TM-100421, 1988.

${ }^{10}$ Anderson, Bianca Trujillo, Robert R. Meyer, Jr., and Harry R. Chiles, Techniques Used in the F-14 Variable-Sweep Transition Flight Experiment, NASA TM-100444, 1988.

${ }^{11}$ Obara, Clifford J. and Bruce J. Holmes, FlightMeasured Laminar Boundary-Layer Transition Phenomena Including Stability Theory Analysis, NASA TP-2417, 1985. 
Public reporting burden for this collection of information is estimated to average 1 hour per response, including the time for reviewing instructions, searching existing data sources, gathering and maintaining the data needed, and completing and reviewing the collection of information. Send comments regarding this burden estimate or any other aspect of this collection of information, including suggestions for reducing this burden, to Washington Headquarters Services, Directorate for Information Operations and Reports, 1215 Jefferson Davis Highway, Suite 1204, Arlington, VA 22202-4302, and to the Office of Management and Budget, Paperwork Reduction Project (0704-0188), Washington, DC 20503

\begin{tabular}{|l|l}
\hline 1. AGENCY USE ONLY (Leave blank) & 2. REPORT DATE
\end{tabular} August 2000

\section{TITLE AND SUBTITLE}

Summary of Transition Results From the F-16XL-2 Supersonic Laminar

Flow Control Experiment.

\section{AUTHOR(S)}

Laurie A. Marshall

NASA Dryden Flight Research Center

P.O. Box 273

Edwards, California 93523-0273

9. SPONSORING/MONITORING AGENCY NAME(S) AND ADDRESS(ES)

National Aeronautics and Space Administration

Washington, DC 20546-0001

\section{REPORT TYPE AND DATES COVERED}

Meeting Paper

H-2410

WU 522-24-00-24-00-SLF

8. PERFORMING ORGANIZATION REPORT NUMBER

10. SPONSORING/MONITORING AGENCY REPORT NUMBER

AIAA-2000-4418

\section{SUPPLEMENTARY NOTES}

Presented at the AIAA August 2000 Conferences, Session APA-15 "Effectiveness of Flow Control Techniques," Denver, Colorado, August 14-17, 2000, AIAA-2000-4418.

12a. DISTRIBUTION/AVAILABILITY STATEMENT 12b. DISTRIBUTION CODE

Unclassified-Unlimited

Subject Category 02

This report is available at http://www.dfrc.nasa.gov/DTRS/

13. ABSTRACT (Maximum 200 words)

A variable-porosity suction glove has been flown on the F-16XL-2 aircraft to demonstrate the feasibility of this technology for the proposed High-Speed Civil Transport. Boundary-layer transition data on the titanium glove primarily have been obtained at speeds of Mach 2.0 and altitudes of 15,240-16,764 $\mathrm{m}(50,000-55,000 \mathrm{ft})$. The objectives of this flight experiment have been to achieve $0.50-0.60$ chord laminar flow on a highly swept wing at supersonic speeds and to provide data to validate codes and suction design. The most successful laminar flow results have not been obtained at the glove design point, a speed of Mach 1.9 at an altitude of 15,240 m $(50,000 \mathrm{ft})$; but rather at a speed of Mach 2.0 and an altitude of 16,154 m $(53,000 \mathrm{ft})$. Laminar flow has been obtained to more than 0.46 wing chord at a Reynolds number of $22.7 \times 10^{6}$. A turbulence diverter has been used to initially obtain a laminar boundary layer at the attachment line. A lower-surface shock fence was required to block an inlet shock from the wing leading edge. This paper discusses research variables that directly impact the ability to obtain laminar flow and techniques to correct for these variables.

F-16XL, Hot-films, Laminar flow control, Suction, Transition.

15. NUMBER OF PAGES

13

16. PRICE CODE

A03

\begin{tabular}{|l|l|l|}
\hline 17. SECURITY CLASSIFICATION & 18. SECURITY CLASSIFICATION & 19. SECURITY CLASSIFICATION \\
OF REPORT & OF THIS PAGE & OF ABSTRACT \\
Unclassified & Unclassified & Unclassified \\
\hline
\end{tabular}

20. LIMITATION OF ABSTRACT

Unlimited 